\title{
International researcher mobility and knowledge transfer in the social sciences and humanities
}

Chris Coey, Research and Knowledge Exchange, University of Salford, Salford, UK

doi.org/10.1080/14767724.2017.1401918

\section{ABSTRACT}

This article explores knowledge outcomes of international researcher mobility in the social sciences and humanities. Looking in particular at international experiences of longer durations in the careers of European PhD graduates, it proposes a threefold analytical typology for understanding the links between the modes, durations, and outcomes of this mobility in terms of the exchange of codified knowledge; the sharing of more tacit knowledge practices; and the development of a cosmopolitan identity. The findings suggest that, under the right conditions, there can be an important and transformative value to longer stays, which can lead to enduring outcomes in terms of knowledge production and innovation and the spatially distributed networks that sustain it.

KEYWORDS: Knowledge transfer, international mobility, research careers, social sciences and humanities

\section{Introduction}

Long-term trends of globalisation have set the context for the internationalisation of higher education across all its functions and aspects. Perhaps the most visible dimension of internationalisation is the mobility of students, faculty, and degree programmes across borders. Whilst there are historical antecedents to these phenomena, there are important differences in terms of scale, geographical patterns, and the role of ICTs and transport technologies that characterise modern forms (Waters and Leung 2013; Welch 2008). Importantly, policymakers have come to view universities as key hubs in the flows of knowledge resources across borders and as mechanisms for capturing and exploiting these resources at regional, national, and local levels (Altbach and Salmi 2011; European Commission 2010; OECD 2007).

The mobility of faculty and researchers remains relatively underexplored compared to that of students (Mihut, de Gayardon, and Rudt 2017), although a growing body of research has begun to shed light on the scale, patterns, and complexities of the former across borders, disciplines, and career stages (Auriol 2010; Huang, Finkelstein, and Ros 2014; IDEA Consult 2013; Jöns 2007). Definitive assessments are difficult, not least because of missing data, differing definitions, and lack of comparability across national cases (Teichler 2011). Nevertheless, levels of international researcher mobility appear to be high: a recent study found that within 10 years of the award of their PhDs, across the EU27 countries, 41\% of researchers had undertaken international stays of less than three months, and $30 \%$ had stays of three months to one year (IDEA Consult 2013). Although the precise mechanisms through which outcomes are achieved are not well understood, faculty and researcher mobility is strongly associated with an increase in productivity (Adams 2013; BIS 2011; Rostan and Höhle 2014) and other benefits to both the host and sending countries and institutions (Jöns 2015; Mahroum 2000b; Williams and Balaz 2008).

The purpose of this article is to review the ways in which theorisations of knowledge and mobility can contribute to the understanding of the knowledge outcomes of longer episodes of international mobility in the social sciences and humanities, drawing for its analysis upon the findings of an 
international study of research careers in these fields. Its main contribution is to propose a threefold analytical typology with which to understand different functions, modes, and outcomes of this mobility. The first category focuses on the mobilities undertaken to acquire and transmit explicit and codified knowledge; the second explores more tacit, socially embedded knowledge practices and the processes of meaning making; the third looks at the cosmopolitan identities and competencies that can emerge in the course of professional lives that are highly mobile. The paper begins with a review of theoretical perspectives on knowledge, disciplines, and international researcher mobility before presenting a qualitative analysis of interviews conducted with social science and humanities PhD holders who had histories of international mobility.

\section{Knowledge and knowing in socio-spatial contexts}

The nature of knowledge is empirically complex, theoretically contested, and has been explored from a range of philosophical, sociological, cognitive, organisational, and technical perspectives (Williams and Balaz 2008). In one sense, knowledge can be viewed as something that can be possessed or held in explicit or tacit form (Nonaka and Takeuchi 1995; Polanyi 1958, 1966). In this view, explicit knowledge is that which can be expressed qua knowledge, stored (for example, as texts), and relatively easily transmitted and received. Tacit knowledge, on the other hand, is that which is embedded in practices and assumptions, cannot be easily articulated, and may not even be understood as knowledge by those who possess it. Neither Polanyi nor Nonaka propose that the relationship between the two is binary, but rather that it should be seen as existing on a continuum, overlapping, and always embedded in systems of socially constructed signs and languages (Abel 2008; Meusburger 2008; Williams and Balaz 2008). Elsewhere, Blackler (1995) categorises knowledge according to its relationship with a bearer (embrained or embodied), collective social and cultural practices (encultured or embedded), or representations and media of transmission (encoded). Emerging from these attempts to disaggregate different forms of explicit and tacit knowledge is a sense that knowledge is, in fact, socially situated in processes of 'knowing' that are dynamic and contested.

A socially situated view points to the significance of communities, cultures, beliefs, and practices. Knowledge communities are characterised by a number of tensions between stability and fluidity in their membership and practices, and between the permeability and impermeability of their boundaries. Communities are essential contexts for learning and the exchange of knowledge (Wenger 1998), they shape the ways in which community members produce new knowledge (KnorrCetina 1999), and they are constituted by discourses that are the subject of political struggles (Meyer and Molyneux-Hodgson 2010). Amin and Roberts (2008) have observed that different knowledge communities exhibit different modes of knowing according to the knowledge used and produced, the nature of social interaction, the kind of innovation undertaken, and the organisational dynamic of interaction. Of particular interest here is the 'epistemic/creative' form of knowing, which is characteristic of communities of highly knowledgeable experts who are recognised as such by their peers, engaged in problem- and time-specific collaborations, are highly self-motivated, demonstrate shared professional and ethical visions, and work in structured but loose contexts in which time for reflection and opportunities for serendipity contribute to sometimes radical innovation.

An important feature of knowledge communities is that they are not necessarily contained by organisational or territorial boundaries. Amin and Roberts (2008), therefore, argue that the knowledge and other social transactions that sustain communities include both physical and virtual mobilities of varying durations, which together constitute what the authors term 'heterogeneities of proximity' (365). Complementary to this view is the observation that individuals (as opposed to 
communities) draw on a portfolio of virtual and physical mobility practices to fulfil professional (and family) roles (Storme et al. 2016). Such diverse patterns of mobility and proximity enable the transmission of knowledge not just within distributed communities but also between different communities that may or may not be spatially proximate. In such cases, the mobility of people acting as brokers or boundary spanners (Wenger 1998) provides a 'pipeline' (Bathelt, Malmberg, and Maskell 2004) through which knowledge moves. Boschma (2005) argues that in order for the transmission of knowledge to take place and to have value, communities of practice must exhibit both similarities and differences in terms of their cognitive, organisational, social, institutional, and geographical characteristics. The right balance between sameness and difference enables mobile brokers to move between communities, and to identify and make use of 'unusual' knowledge.

\section{Transformative mobility}

The concepts of brokerage and boundary spanning shift the scale of analysis to the individual, and to the importance of recognising the subjectivities involved in knowledge activities. Moreover, placing knowledge activities in their social and transnational contexts foregrounds the role of the international training, skills, competencies, and perspectives of members of disciplinary and knowledge communities. Williams and Balaz (2008) have discussed the 'particular capacity for reflection' (44) evident in migrants engaged in knowledge transfer across borders. This reflective capacity is associated with greater or lesser degrees of personal transformation, of a variety of international activities of different qualities and durations, and with a range of knowledge objectives and outcomes. In one very straightforward sense, there is a 'safari' model of mobility (Ackers 2013; Hantrais 2009) in which, through fieldwork, for example, a researcher travels in order to collect data and returns home. Similarly, Robinson-Pant's (2009) exploration of international PhD student practices found that, for some, instrumental reasons (i.e., to obtain a $\mathrm{PhD}$ ) were a core motivation for adopting the practices of their hosts.

However, Robinson-Pant's (2009) study found that others viewed themselves as future agents of change on their return home. This second category reflects what can be described as transnational approaches, characterised by the socialisation of mobile individuals into multiple socio-spatial communities that can be either territorially distinct or nested. For example, whilst much of the empirical and theoretical literature concerns the mobility between a small number of different national contexts, Rossi (2008) argues that in more peripheral countries academics are required to develop a 'multi-layered academic citizenship' incorporating practices and cultures from both home and more powerful internationally dominant systems.

A range of skills, competencies, knowledges, and dispositions might be acquired and deployed through international mobility. These could include curricular knowledge, intercultural skills, and critical thinking (van Oorschot 2014), or analytic, emotional, creative/imaginative, and behavioural skills (Koehn and Rosenau 2010). Internationally mobile academics (Larner 2015) and doctoral students (Bilecen and Faist 2015) are examples of brokers who, through their socialisation in more than one country, are able to identify knowledge from one place that can be transferred and applied in another. Central to this brokerage is the reciprocity, trust, and solidarity established over time, which binds networks as researchers disperse geographically in their careers. Moreover, the mobility of researchers between countries can have a significant impact on knowledge transfer (particularly where patterns of exchange and circular mobility are established), the establishment of transnational knowledge networks, and the development of a disciplinary community and knowledge centres in both host and sending countries (Jöns 2015; Velema 2011). 
Going beyond transnational models of international situatedness, Kim (2010) explores the development, through socialisation in multiple contexts, of a sense of deterritorialisation, or 'outsiderhood', in the practices and identities of internationally mobile scholars. This, in turn, enables a constructive engagement with otherness and an ability to translate across different ethnocultural and disciplinary identities. Kim's notion tends more towards a sense of cosmopolitanism, or a meta-level engagement not only with place- or community-specific difference but also with different modalities of difference. This resonates with Said's notion of the 'exilic intellectual' deployed by Fahey and Kenway (2010). For Fahey and Kenway, '[e]xilic intellectualism means positioning oneself as an outsider in opposition to orthodoxies' (631). In particular, it means taking a critical stance towards knowledge and the relations and geographies of power that produce it.

\section{Disciplinary perspectives}

It is important to consider the ways in which the discussion so far applies to disciplines, especially to the extent that there are distinct knowledge and mobility practices both between and within disciplines (Ackers and Gill 2008; Cañibano, Otamendi, and Solís 2011; IDEA Consult 2013; Jöns 2007). The value of a disciplinary perspective is, firstly, that it combines both the cognitive and social dimensions of knowledge. Secondly, it moves beyond a relatively generalised analysis to one that identifies and explores specific knowledges and practices. However, it is important to note that the study of disciplines is itself contested, multi-disciplinary, and focusing on a range of different concerns. For example, Krishnan (2009) has identified six distinct disciplinary perspectives on disciplinarity (from philosophy, anthropology, sociology, history, management, and education), only one of which (philosophy) directly addresses knowledge.

Perhaps the best-known analysis of disciplines is the one that has been developed by Becher and Trowler (2001). Becher and Trowler (2001) employ a typology of disciplinary knowledge based on the degree to which disciplinary knowledge exhibits paradigmatic cohesion (hard equals more, soft equals less), and the degree to which they are pure (i.e., abstract) or applied. From these two dimensions, the authors identify four knowledge-discipline categories: hard-pure (for example, physics), soft-pure (for example, the humanities and some social sciences), hard-applied (for example, technological subjects such as mechanical engineering), and soft applied (for example, social sciences such as education or law). It is instructive to observe that Becher and Trowler place the social sciences and humanities in two categories, acknowledging their internal diversity.

The socio-spatial distribution of disciplines as both local and international points to the important role of mobility in their organisation and maintenance. Indeed, it is possible to see disciplines as communities of practice (Becher and Parry 2005) broadly united by institutional proximities achieved through common foundational texts, theories, methods, leading figures, networks, and relationships, yet manifesting locally in specific national-cultural contexts, institutions, and departments in idiosyncratic ways. In order to understand specific research practices both in terms of knowledge and mobility, Jöns (2007) develops a typology along three dimensions: the degree of materiality, standardisation, and abstraction, yielding a sophisticated and fine-grained analysis of the relationships between these factors.

Jöns (2007) finds that in fields in which knowledge resources exhibit a strong degree of materiality and low levels of standardisation, mobility is a more important factor in its production. Importantly, she recognises that, whilst individuals (the bearers of embrained and other forms of tacit knowledge) may be relatively mobile, their concentration into groups at key sites lends them a place-specific material quality that echoes Mahroum's (2000a) notion of 'magnet' institutions and departments. This observation of a kind of 'critical mass' of expertise in particular places is 
complemented by the observation of the place-specifity of some, but not all, socially situated practices. For example, writing practices in some branches of the social sciences use specific, technical vocabularies that are commonly shared, whilst others are very individually distinct.

\section{The role of time}

Understanding the knowledge outcomes of mobility from a socially situated perspective means taking into account the ways in which, through mobility, meaningful engagement in geographically dispersed communities is influenced by the duration of a stay. From a technical viewpoint, of course, there can be no convenient indicator of what constitutes 'meaningful' engagement. However, neither is there a consensus on what might count as a short, medium, or long stay. Scholars working on analysis of the data from the Changing Academic Profession study, for example, have this to say:

[Mobility] may vary from the few minutes needed to send an e-mail abroad to a stay lasting several generations. The length of mobility has to be understood as a continuum along which it is possible to distinguish short-term vs. long-term mobility, several degrees of temporariness, and international migration vs. other forms of human mobility. (Rostan and Höhle 2014, 81)

In practice, policymakers and researchers make distinctions between longer and shorter durations of stay. The cut-off point for short stays ranges from 1 month (Cañibano, Otamendi, and Andújar 2008) to 12 months (Hoffman 2009), and up to two years (Rostan and Höhle 2014). A distinction is also made between temporary and permanent, in which any stay greater than two years is regarded as permanent (Cañibano, Otamendi, and Solís 2011). This lack of consensus reflects current thinking on migration and mobility as existing on a continuum of temporal practices, and as being 'multiple and spatially capricious' (King 2002, 98).

The subjective dimension of duration concerns an individual's motivations and intentions, and the degree to which she perceives her stay as meaningful, transformative, and/or engaged (King 2002; Rostan and Höhle 2014). In a concrete sense, these subjectivities manifest in an engagement with the host context, leading over time to a degree of 'stickiness' in local communities (Williams, Balaz, and Wallace 2004). The concept of stickiness relates to the need for time in place to develop social and other attachments, including professional and friendship networks (Ackers and Gill 2008). Moreover, there do appear to be time-related knowledge outcomes of longer stays in particular. Longer stays, for example, are associated with the transfer of more complex and tacit forms of knowledge (Edler, Fier, and Grimpe 2011), greater opportunities for diverse and serendipitous encounters (de Filippo, Casado, and Gómez 2009), greater productivity (Jonkers and Tijssen 2008), future collaborations and mobility (Ackers and Gill 2008), as well as non-job-related personal and cultural benefits (Jöns 2002). These outcomes need to be seen, however, in the light of recent work that has begun to identify specifically the outcomes of short-term modes of mobility (Ackers 2010; Borchgrevink and Scholz 2012) and the ways that short and virtual episodes of mobility interact to sustain a range of communities and knowledge practices (Storme et al. 2016).

From the discussion above, several points can be distilled that frame the analysis that follows. Firstly, knowledge does not consist of discrete, abstract, external 'packets' of information. Rather, a range of knowledge types, ways of knowing, skills and competencies, learning and communicating are involved, all of which are embedded in socially situated processes. Secondly, all knowledge practices involve the engagement of individuals in the communities, disciplinary and other, in which knowledge is produced, interpreted, stored, and applied. Such communities have many spatialtemporal forms, not all of which involve physical proximity. Thirdly, the diversity of knowledge types 
and ways of knowing, both between disciplines and within them, explain the existence of an equally diverse range of mobility practices. Fourthly, engagement with different communities across national and other boundaries, through a variety of modes and including mobilities of different duration, can be transformative for those who take part. Finally, the duration of a stay can play an important role in facilitating the transfer of certain types of knowledge.

\section{Biography and life course}

There is an important caveat to the professional and knowledge dimensions of mobility, which is that mobility choices are strongly influenced by the biographies and life courses of individuals. Jöns, Mavroudi, and Heffernan (2015) illustrate how individuals with existing biographical links through ancestry or marriage, as well as those with no pre-existing link but an interest in the culture and language of their hosts, can be motivated to take part in knowledge activities with international peers. A personal interest in a place, or an openness to mobility in general, might emerge from family background or educational experiences (King and Ruiz-Gelices 2003; Murphy-Lejeune 2002). Importantly, as Jöns, Mavroudi, and Heffernan (2015) point out, a personal affinity to a particular place can be reinforced or created via mobility in order to recruit new members to place-oriented networks. Moreover, countries such as the UK and the USA, with current or past linguistic and cultural dominance, tend to benefit from a sense of familiarity and a higher global profile than competitor countries (Adsera and Pytlikova 2012; Altbach 2007; Kim 2009 Kim), an advantage that Mahroum (2008) refers to as 'legacy opportunities' (13).

Other work around mobility highlights how the costs of mobility, for example, in terms of absence from home and caring responsibilities, can be prohibitive and detrimental to a career. This is both gendered and related to stages of an individual's life course (Ackers and Gill 2008; Jöns 2011).

Storme et al. (2016) stress how the obligations of presence in both family and professional lives can come into conflict and must be negotiated. Recognising these and other barriers to mobility brings into focus the importance of understanding that the potential for mobility, or 'motility' (Kaufmann, Bergman, and Joye 2004), is a form of capital that integrates both social and physical space, and to which individuals do not have equal access.

\section{The study (POCARIM)}

The analysis presented here draws upon research undertaken in the course of a European Commission FP7-funded project across 13 countries, ${ }^{1}$ Mapping the Population, Careers, Mobilities and Impacts of Advanced Research Degree Graduates in the Social Sciences and Humanities (POCARIM). The project consisted of several phases. In the first phase, national- and European-level surveys of existing research (Gustafsson and Hanson 2013), policy (Bitusikova 2012), and data sets (Cañibano et al. 2013) were conducted. In the second phase, an online survey was carried out that generated 2723 responses (Kupiszewska et al. 2013). Finally, 25 interviews were carried out in each country (325 in total) which were coded and analysed in NVivo qualitative software.

This paper analyses the interviews only, chosen according to a number of criteria. Firstly, interviewees must have indicated in the interview that they had experiences of international mobility from their doctoral phase onwards. Secondly, their mobility had to have been in the context of a higher education or research role. Thirdly, they were included if they indicated a perception that at least one international mobility episode had been of a significant duration or had had meaningful

\footnotetext{
${ }^{1}$ The countries in which the study was carried out were France, Germany, Hungary, Italy, Latvia, Norway, Poland, Portugal, Slovakia, Spain, Switzerland, Turkey, and the UK
} 
outcomes in terms of knowledge. As noted above, deciding on what makes an experience 'meaningful', and what counts as a 'significant' duration, is highly subjective both from the point of view of the participant and the analyst. The boundaries were, therefore, drawn quite broadly, allowing for a wide sample which illustrated, firstly, the range of outcomes (in particular vis-à-vis knowledge) that were perceived to be significant. Secondly, it enabled analysis of the relationships between mobility and outcomes from both directions, i.e., both the ways in which a 'meaningful' outcome could be achieved via a range of mobilities and, on the other hand, the kind of outcomes produced by relatively long stays (i.e., several months or more).

From the 325 interviews conducted in the POCARIM study, 33 were identified as fitting the criteria for inclusion in the analysis that follows. Table 1 lists the interviews that have been used (not all are directly quoted), the country in which they were conducted, the nationality of the interviewee, and the field of PhD.

\section{Table 1. Characteristics of interview sample $(n=33)$ (see below)}

\section{Mobility and knowledge outcomes}

\section{Duration and timing of longer term stays}

For some of the interviewees, national or institutional norms informed their perspectives as to whether stays abroad might count as short, medium, or long term. One Swiss interviewee spoke of how national mobility grant terms meant that three months was the minimum desirable stay, and how any shorter 'would not necessarily count as an abroad experience in case of applying for a position' ( $\mathrm{CH} 11$ ). From a subjective point of view, though, relatively short visits were perceived to be sufficient for certain professional outcomes:

... just three months away, if well planned, are enough to understand what we have to understand. (IT27)

There is evidence of mobility being perceived somewhat instrumentally in the previous two comments. In contrast, the impact of a relatively short stay of just one month in Greece to attend a summer school was profound on a personal and cultural level for this interviewee:

We travelled over whole Greece. I saw all the most prominent archaeological sites, all those places and cities. At that time I fell in love with Greece very much. It is one thing when you just go there for a week. Different thing is when you are there for a month or even longer. When you travel, you learn it all from the inside. (LV13)

On the whole, however, there was a reasonable level of consensus that a longer period abroad could lead to greater benefits. For some, these benefits were professional:

Anyone that wants to work in research must go abroad, as a minimum for 2 or 3 years.

Working abroad helps to see how others work. This is vital. (ES23)

Others echoed Jöns' (2002) findings that the outcomes of longer term research mobility are not necessarily scientific but personal and cultural, in some cases embedding these alongside professional benefits:

The other thing, on a more personal level, is that spending half a year in another culture is also definitely of benefit to anyone. (HUO3) 
In the terms of the understanding, networks, knowledge, I learned how to study. All kinds of ways. It was a year away. Intensive studies. Intensive partying. Different system. All that.

That changed everything for me. (LV05)

The significance of timing of mobility was evident, including international experiences prior to doctoral studies (King and Ruiz-Gelices 2003; Murphy-Lejeune 2002). A handful reported childhood experiences of relocation due to parents' work or cosmopolitan family histories, including the following Turkish interviewee:

... my parents studied in Germany, my grandparents studied in Germany, my great grandparents studied in Germany, I was the fourth generation. So it was normal to go. They sent me to Germany, I never thought of something else. (TR02)

In many other cases, doctoral or post-doctoral training had been undertaken overseas or had included international study or research stays. These experiences were perceived to have had meaningful impacts on interviewees in almost all cases. However, two factors affecting impact were reported. Firstly, mobility was valuable when it facilitated socialisation into the cultures, practices, and networks of multiple sites. Hence undertaking an entire PhD programme in one place, even outside of one's home country, was associated with a range of barriers to return and to knowledge transfer. Secondly, and conversely, a lack of engagement with the host community was associated with a corresponding lack of socialisation, communication, and positive outcomes. This second point is captured by the following quotation, in which a Norwegian interviewee reports his observations of his co-nationals studying and working in the USA:

... they would go with their entire family, they would stay there, they would [live] in a primarily Scandinavian city with other Scandinavians in one centre and do their own research. I don't really know how much they were integrated with what was going on there so, it's not I would say internationalisation if you do the same kind of things that you do at home, talk to the same people but just in a different setting in a different time. It becomes a kind of different cultural experience but it's not really a different academic experience. (NO12)

\section{Types of knowledge outcomes}

The qualitative analysis of the POCARIM interviews points to three categories of knowledge outcome in which longer stays play an important and even necessary role (Table 2). The first accounts for the process of transmitting and acquiring what is conventionally understood as explicit or codified knowledge. The second focuses on knowledge practices that need to be understood in relation to their social and cultural contexts, in other words knowledge that is significantly implicit and embedded. Finally, there is the reflective and transformational reorientation of a mobile individual towards more cosmopolitan knowledge practices, labelled and understood here as a form of identity.

Table 2. Knowledge outcomes of international visits. (See below)

\section{Exchanging knowledge}

Superficially, some knowledge and knowledge practices might be categorised as 'international' insofar as it is possible to move them easily across borders and between communities in the form of discrete packages of information. However, even in its most explicit, codified and abstract forms knowledge must be understood through signs and symbols that take time to learn and bear the imprint of the communities that produced them (Abel 2008). Understanding knowledge in terms of 
disciplines and their practices offers powerful explanatory tools for understanding the value of copresence and duration even in these apparently straightforward transactions (Becher and Trowler 2001; Jöns 2007).

For example, physical resources such as libraries, archives, museum collections, archaeological digs, and so on tend to be place-specific and relatively immobile. Conceptual resources, such as skills and knowledge, might be explicit and codified, and/or embodied in actors located in particular places though potentially mobile. Many such resources might also be available in the form of texts or other resources that can be digitised and transmitted virtually, for example, in the form of electronic books and articles, scans and images, online discussion groups, or audio-visual recordings. In the first case, it would appear that mobility is necessary, but in the second it is not. Storme et al. (2016) nevertheless highlight the importance of co-presence to collective meaning making in an era when vast amounts of information is codified and mobile in electronic form. However, even where mobility is necessary it is important to interrogate what, if any, value can be added by extending the duration of that access or co-presence.

Many interviewees reported a strong perception that even in the acquisition and transfer of relatively explicit knowledge, co-presence, and duration added value. The first reason for this was simply that, to the extent that time in place with peers or resources enabled knowledge transfer, more time allowed for more and a greater variety and depth of knowledge. A common theme was that of access to library resources abroad that were unavailable at home. Although books in physical or electronic form are highly mobile and increasingly accessible regardless of location, even a week or two in a good library was frequently reported to have been an immersive and high impact event. Equally, longer stays offer opportunities to take part in other activities in a host institution involving peers, experts, and both formal and informal learning opportunities. The tacit dimension to all these activities is evident in the following quotations:

Nowadays we can get a hold of information [and] books everywhere, [through the] internet and this and that. But it is another thing when you see an expert in that field standing in front of you and talking to you, even being in that environment and witnessing that and witnessing all that energy and talking, it's a lot of contributions. You understand it at a different level. And you have the opportunity to ask questions face-to-face and then you have the opportunity to talk to other colleagues, and discuss things with them and see how they're dealing with issues in their home countries. And that's very enriching. (TR05)

... there were all kinds of lectures about different topics and there was always an expert lecturer invited to speak. For example some lectures were about how to publish, how to find the right journals and how to reference properly. We also had technical English and were taught how to write in English and how to conduct oneself at conferences. (SK02)

To some extent, this tacit dimension is relevant also to the second factor, which is that co-presence over longer periods allows for knowledge exchange to be negotiated and targeted, a key benefit of 'meetingness' according to Storme et al. (2016). Relevant knowledge can, therefore, be transferred quickly, perhaps in higher volume, and with an understanding of the intentions and perspectives of its producers and users in the host environment. The interviewee quoted above also spoke of working closely for the period of her stay with a host supervisor, an expert in her field, who guided her through literature, concepts, and methods relevant to her work. Whilst it is arguable that other strategies could have achieved similar outcomes in this case, it is clear that mobility and sustained co-presence added great value: 
[My host supervisor] studied new things with me and brought me lots of materials. We discussed a lot. He also really helped me with the methodology. He had the SPSS system which we don't have. We didn't have online journals at our university. There you have an unlimited access to journals and other publications. (SKO2)

\section{Sharing knowledge practices}

The second type of knowledge outcome explored here is categorised as the sharing of knowledge practices. Spatially it can be characterised as 'transnational', which refers to enduring social connections between two or more sites that are located in different national-cultural contexts (Basch, Glick Schiller, and Szanton Blanc 1994; Faist 2000; Levitt and Glick Schiller 2004). The phrase 'knowledge practices' emphasises the embedded, processual, and social nature of the knowledge types in focus. There are at least five features of transnational knowledge practices, the first of which is that they are embedded in place-specific contexts and in the languages and practices of particular communities. The tacitness of this feature was evident in the ways in which the language used by interviewees alluded to its elusive and intangible nature. For example, interviewees referred to the 'milieu', 'environment', or 'atmosphere' they experienced during their stays abroad. Others parsed this into ways of knowing and ways of doing, reporting on the challenges of orienting themselves to new ways of looking at research problems, and to the opportunities to acquire new study and research skills.

Interviewees' comments also reflected a more or less explicit recognition that the social nature of knowledge practices had both a temporal and spatial quality. For example, one Hungarian interviewee noted the importance of developing meaningful friendships in order to achieve his desired knowledge outcomes:

The difference [between Hungary and abroad] is how and to what extent they plan the project, and how consistently this plan is applied throughout. They're really good at that. What I really want to learn from them is how things can be done, and you can only see this if you get to be friends with them. (HUO3)

Another explicitly links the social dimensions of knowledge and its practices to the potential for mobility:

There is no way that you can say that ideas or approaches and ways of doing different things would just circulate because they are very much embedded in cultures. (DEO4)

Aalbers and Rossi (2007) have explored these issues for non-English-speaking scholars negotiating access to mainstream (i.e., Anglo-American) publications and knowledge communities that are unfamiliar with their disciplinary traditions and literature. These concerns resonated in this study in the comments of a number of interviewees who made the connection between the socio-cognitive dimension of their work and the need for proficiency in both disciplinary and national or local languages. This Italian interviewee sees the development of these competencies as an important outcome of an international stay. He outlines some of the benefits:

... you understand what people really mean when they talk in conferences, you understand what you study ... . You understand better a language, which is to understand a society, [to understand] what I am supposed to do. (IT27)

A second feature of transnational knowledge practices is the emergence of comparative perspectives that facilitate the emergence of an understanding of differences in ways of working, knowledge, and learning, career paths, levels of international engagement, and broader features of 
different cultures. Interviewees' comments often articulated a perception of a deficit in one country in relation to another, with those from geographically or scientifically peripheral countries tending to view international stays as a means of acquiring better or more up-to-date knowledge or skills. One Latvian sociologist, for example, spent a year as an exchange student in Finland, and discovered that 'the way we were taught philosophy [in Latvia] was simply a mess'. He returned from his stay 'with a clear thought that I want things to be like in Finland for us here one day'. The value of such comparative perspectives is expressed in the quotation from an Italian PhD who spent several months in Germany during her doctoral training:

The experience in Germany was certainly really good, in the sense that basically you see a different context, to measure yourself, no? Against a different reality, a different culture. It's always an enrichment, you can't get away from that. (IT23)

A third feature is that this understanding of the different contexts that frame knowledge, and the ability to make comparisons between them, underpins the role of internationally mobile academics as brokers. As agents of knowledge transfer, they bridge multiple locations and they translate and apply knowledge and practices into new contexts, often leading to either place-specific or more general innovations in particular fields. The following quotation is typical of interviewees who went overseas with the specific intention of bringing back knowledge to apply at home:

The only thing I was planning when I was going to the States was to learn how to do research. Because I'm sure you know that the American academy is very different from the Turkish academy. People are different there. So, I just wanted to breathe the atmosphere, to do certain things. That is why I wanted to come back from the States, to apply what I learned to Turkish society, to teach, to contribute to Turkish academy, basically. These were my motivations. (TRO3)

Similarly, one of the Latvian interviewees had studied in the USA, but was very clear that her groundedness in both the needs of her home country and the opportunities of the USA were important. She spoke of her need 'to be rooted and connected and actually have a reason to study and go do what I am doing in the States' (UK01). Another Latvian talked about a scholarship she had won to the USA, which gave her a sense of the value of an international orientation. Her new perspectives were useful not only in understanding how things are done elsewhere but enabling her to place Latvia, a relatively small country, in a wider context.

Fourthly, undertaking a stay abroad can be an important factor in the development of a sense of oneself and one's role in the international context of a discipline or field. One element of this is the development of professional networks through which opportunities, collaborations, and other benefits are accessed. Commenting on the relationship between duration of stay and network development, FR22 said simply: 'When you stay enough time in one place, your network grows a lot.' Importantly, understanding the broader contexts of one's work can contribute to a more confident professional identity. Through mobility, HU03 says,

I get to know young people in my field, and if a certain topic comes up, I know who is working in that area. I saw how people work in the most distinguished places in the field. Which reassures me. I always had this sense of frustration, that 'oh, they're so good and so smart', but that's not where the difference lies. The difference is how and to what extent they plan the project, and how consistently this plan is applied throughout. They're really good at that. 
Finally, the previous point speaks to rather more transformative outcomes, evident in many of the interviewees' accounts. On the whole, it reflects a meaningful sense of orientation to the cultures and practices of another place, which can generate a sense of attachment and trust. In turn, this can contribute to the development of follow-up mobility of students, doctoral researchers, post-docs, and professors (Jöns 2009). In some cases, however, the personal transformation of the mobile researcher is even more profound, and a more reflective cosmopolitan orientation emerges.

\section{Developing a cosmopolitan identity}

In some of the interviews, experiences of transnationality had begun to engender a more reflective sense of self, which was less grounded in specific places and communities but rather characterised by a sense of detachment, of being 'never quite at home again' (Hannerz 1990, 248). Some interviewees spoke of long term or even life times of mobility that had led them to feel 'deterritorialised' (DE04) or 'disassociate[d] a little bit from any kind of cultural marker' (CH05). Another commented on encounters with 'diverse realities' (PTO2) that had led to a sense of being outside of any particular community. Rather, there was an orientation to places and communities that recognised not just specific differences which could be compared but acknowledged that the nature of difference itself could vary. Professionally, this could lead to a distance and adaptability in relation to different cultural epistemic communities, as the following comment illustrates:

[Interviewer: When you talk about community or society, about which community do you think of? Would it be Switzerland or would it be the US community or society?] So for me it is more like an abstract ... Depending on where you do research, you always do research within a community. Like right now I'm doing research in this community, and this community has some needs and some particularities. When I go back home to do some research there it would be another community, with its all specific needs and rules and functioning. I think there are many different communities depending on what you do. (CH15)

There is, therefore, a conceptual shift from the social to the personal, and away from relatively static notions of place- or community-specific belonging, perceptions, practices, and knowledge. Cosmopolitan identities emerge from reflexivity and flexibility, tolerance of difference and ambiguity, and self-confidence. Having undertaken a long-term move to the USA, one German interviewee had discovered that she was 'pretty flexible in terms of adapting to different cultural standards'. Like others who had relocated, adapted, and even thrived, she was confident that she could do it again. The perspectives of this interviewee were informed by her relationship with a partner who was neither German nor American. In negotiating location decisions, therefore, she had to remain open and flexible, and recognise the possibility of an unsettled future. She perceives this as something of a dilemma facing people in her position:

I think [where I might move to] really depends. It is one of these questions that people, international people have to figure out for themselves and constantly revise these decisions too ... do you move back to Germany, do you move to your partner's country, then maybe it's really great to stay in the US, maybe that's a nice compromise because this is where we live now, this is where we met. (DE01)

This orientation towards place and mobility, and to different cultures and practices, is an expression of more than high-level generic skills that are applicable across both familiar and unfamiliar contexts, but of an identity and an orientation to the social world and to knowledge that amounts to a 'stance towards diversity itself' (Hannerz 1990, 239). It is this stance that, for Hannerz (1990), enables the cosmopolitan to function as a broker between communities. One interviewee, for example, 
emphasised the importance of approaching research and research questions in a way that recognises knowledge as situated in the perspectives of others. She saw this as 'a view of the world, [of] how different people live' (LV25). Another echoed this point, emphasising that it cannot necessarily be assumed that people do things the same way in different places, or even that the nature of the differences are predictable. She notes that the differences that exist are social, embedded in roles and practices. Essentially, these differences are:

... about collaboration and about people: you look at the ways they look at the things. You understand that maybe in other countries there is a very strict hierarchy - 'professor said' and so on. That professor will never run with a teapot and so on. Here we say, 'I am a professor, but if I have to, [I'II] wash the floor in the auditorium'. (LV23)

\section{Conclusions}

The relationship between international mobility and knowledge transfer must be understood in the context of diverse patterns of physical and virtual mobility. These are associated with a range of engagements with the socio-cognitive systems of host and sending countries, and have generated a number of outcomes. Importantly, practices are heterogeneous and 'enfolded' at the level of both the individual (across time) and organisation (across the population). This paper has sought to contribute to the understanding of the relationship between time, mobility, and knowledge by focusing on and juxtaposing, firstly, the experiences (in terms of knowledge outcomes) of individually mobile researchers in the social sciences and the humanities with, secondly, international stays of relatively longer duration. In doing so, it has explored the relationship in both directions, and identified non-deterministic flows of influence suggesting that, under the right conditions, there are significant benefits to longer stays.

In order to make sense of the different outcomes of longer stays, the paper suggests a framework based on a threefold typology consisting of: firstly, straightforward outcomes such as an increase in the volume of more explicit forms of knowledge that is acquired and exchanged; secondly, the emergence of transnational modes of engagement between two - or at least a very limited number - of communities of practice; and, thirdly, the emergence of a transformed and cosmopolitan engagement with 'otherness' that is not place- or community-specific. This paper finds the strongest relationship to be between relatively long stays and transnational knowledge outcomes, in terms of both cultural and subject-specific knowledge and knowledge practices. This is because transnational practices are deeply place- and community-specific, and involve meaningful multiple engagements, socialisation and embedding that increase with growing frequency and intensity of interaction and thus with time. Transnationally oriented researchers are fluent in the communicative, cultural, and knowledge practices in different places, they understand knowledge in the contexts of its production and storage, and are able to translate and reapply it to other contexts with which they are equally familiar.

\section{Disclosure statement}

No potential conflict of interest was reported by the author.

Table 1. Characteristics of interview sample $(n=33)$.

\begin{tabular}{|l|l|l|l||}
\hline Interview code & Country of interview & Nationality & PhD field \\
\hline CH11 & Switzerland & Swiss & Business Studies \\
\hline
\end{tabular}




\begin{tabular}{|c|c|c|c|}
\hline Interview code & Country of interview & Nationality & PhD field \\
\hline $\mathrm{CH} 14$ & Switzerland & Swiss/Mexican & International Relations \\
\hline $\mathrm{CH} 15$ & Switzerland & Swiss & Psychology/Law \\
\hline DE01 & Germany & German & Psychology \\
\hline DE04 & Germany & German & |Linguistics \\
\hline DE19 & Germany & German & Political Science \\
\hline DE24 & Germany & German & Geography \\
\hline ES23 & Spain & Spanish & Geography \\
\hline FR11 & France & Brazilian & Sociology \\
\hline FR14 & France & French & Sociology \\
\hline FR22 & France & Swiss & Sociology \\
\hline HU03 & Hungary & Hungarian & Economics \\
\hline HU08 & Hungary & Hungarian & Economics \\
\hline HU09 & Hungary & Hungarian & Law \\
\hline IT03 & |taly & Italian & Literature \\
\hline IT23 & Italy & Italian & Social Psychology \\
\hline IT27 & Italy & Italian & Sociology \\
\hline LV02 & Latvia & Latvian & Law \\
\hline LV05 & Latvia & Latvian & Sociology \\
\hline LV09 & Latvia & Latvian & Sociology \\
\hline LV13 & Latvia & Latvian & |Linguistics \\
\hline LV23 & Latvia & Latvian & Education \\
\hline LV25 & Latvia & Latvian & Economics \\
\hline NO12 & Norway (resident in Sweden) & Norwegian & History \\
\hline NO13 & Norway (resident in Australia) & Australian & Law \\
\hline PLO4 & Poland & Polish & Demography \\
\hline PT02 & Portugal & Portuguese & Social Science \\
\hline
\end{tabular}




\begin{tabular}{||l|l||l||l||}
\hline Interview code & \multicolumn{1}{|c|}{ Country of interview } & Nationality & \multicolumn{1}{||}{ PhD field } \\
\hline SK02 & Slovakia & Slovakian & Economics \\
\hline TR02 & Turkey & Turkish & Archaeology \\
\hline TR03 & Turkey & Turkish & Psychology \\
\hline TR05 & Turkey & Turkish & Law \\
\hline UK01 & UK & Latvian & Sociology \\
\hline UK06 & UK & British & History \\
\hline
\end{tabular}

Table 2. Knowledge outcomes of international visits.

\begin{tabular}{|c|c|c|c|}
\hline & Knowledge type & $\begin{array}{c}\text { Added value of longer } \\
\text { stay }\end{array}$ & Complications/caveats \\
\hline $\begin{array}{l}\text { 1. Exchanging } \\
\text { knowledge } \\
\text { Focus on } \\
\text { knowledge itself } \\
\text { as 'meaningful } \\
\text { information', its } \\
\text { transmission and } \\
\text { acquisition }\end{array}$ & \begin{tabular}{|l} 
Explicit, codifiable, \\
portable or place \\
bound, not \\
necessarily place- \\
specific
\end{tabular} & \begin{tabular}{|l|} 
Access to variety and \\
quantity (knowledge, \\
skills, training, \\
resources); opportunities \\
to interact with \\
holders/producers of \\
desired knowledge; \\
understanding \\
knowledge in context; \\
tailoring interactions and \\
acquisitions to individual \\
needs
\end{tabular} & \begin{tabular}{|l} 
Longer duration not necessary, \\
many other bodily and virtual \\
forms may achieve more or less \\
the same outcomes
\end{tabular} \\
\hline \begin{tabular}{|l|} 
2. Sharing \\
knowledge \\
practices \\
Focus on the \\
social processes \\
of knowledge and \\
meaning
\end{tabular} & \begin{tabular}{|l} 
Tacit, embedded, \\
comparative, \\
reflective, \\
networked
\end{tabular} & \begin{tabular}{|l|} 
Enables embedding in \\
two or more \\
communities \\
(transnational), acquiring \\
knowledge in context, \\
communication and \\
translation; \\
transformation- \\
orientation to multiple \\
contexts
\end{tabular} & $\mid \begin{array}{l}\text { Need to maintain networks post- } \\
\text { mobility, or risk of network decay; } \\
\text { brain waste or brain drain; } \\
\text { embedding can lead to } \\
\text { entrapment in particular national } \\
\text { labour market or place in } \\
\text { international hierarchies of } \\
\text { institutional/reputational prestige }\end{array}$ \\
\hline \begin{tabular}{|l|} 
3. Developing a \\
cosmopolitan \\
identity \\
Focus on \\
transformations \\
of the mobile self
\end{tabular} & \begin{tabular}{|l} 
Personal, \\
reflective, \\
transformational, \\
orientational
\end{tabular} & \begin{tabular}{|l|} 
Time for personal \\
transformation, \\
development of identity, \\
innovative knowledge \\
practices; improvement \\
of language skills;
\end{tabular} & \begin{tabular}{|l} 
Difficult to identify, possibly rare - \\
or unremarkable - in international \\
research communities; it is \\
possible that it is the spaces \\
rather than the people that are \\
cosmopolitan; significance of
\end{tabular} \\
\hline
\end{tabular}




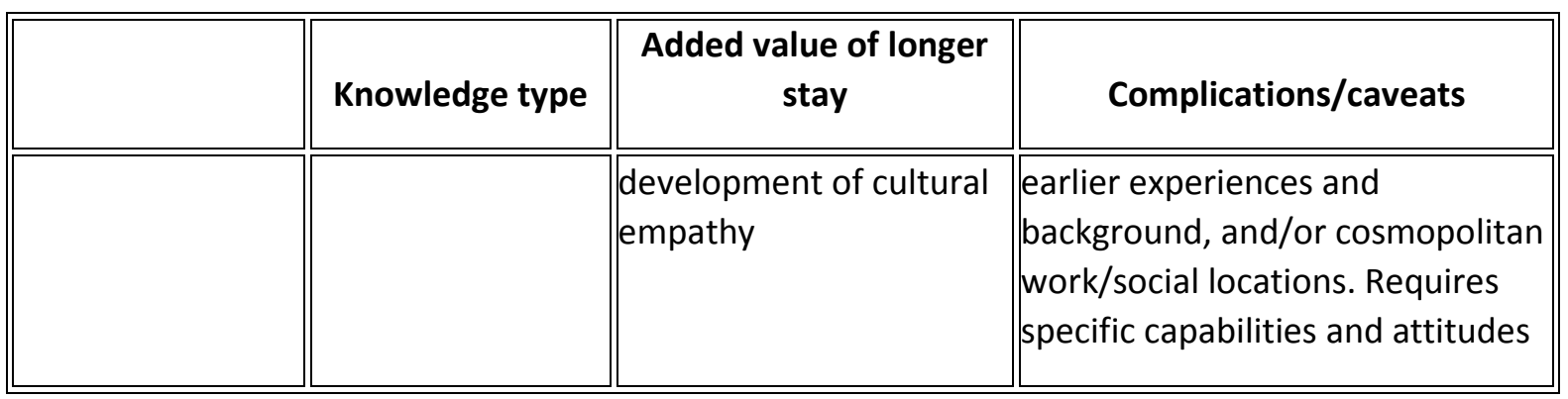

\section{References}

Aalbers, M. B., and U. Rossi. 2007. "A Coming Community: Young Geographers Coping with MultiTier Spaces of Academic Publishing Across Europe." Social and Cultural Geography 8 (2): 283-302. doi: $10.1080 / 14649360701360220$

Abel, G. 2008. "Forms of Knowledge: Problems, Projects, Perspectives." In Clashes of Knowledge: Orthodoxies and Heterodoxies in Science and Religion, edited by P. Meusburger, M. Welker, and E. Wunder, 11-34. Dordrecht: Springer.

Ackers, L. 2010. "Internationalisation and Equality: The Contribution of Short Stay Mobility to Progression in Science Careers." Recherches Sociologiques et Anthropologiques 41 (4): 83-103. doi: $10.4000 /$ rsa.189

Ackers, L. 2013. "Internet Mobility, Co-Presence and Purpose: Contextualising Internationalisation in Research Careers." Sociología y Tecnociencia/Sociology \& Technoscience 3 (3): 117-141.

Ackers, L., and B. Gill. 2008. Moving People and Knowledge: Scientific Mobility in the European Union. Cheltenham: Edward Elgar Publishing.

Adams, J. 2013. "Collaborations: The Fourth Age of Research." Nature 497 (7451): 557-560. doi: $10.1038 / 497557 a$

Adsera, A., and M. Pytlikova. 2012. The Role of Language in Shaping International Migration. Norface Discussion Paper Series. London: University College London. http://www.norfacemigration.org/publ uploads/NDP 14 12.pdf.

Altbach, P. G. 2007. "The Imperial Tongue: English as the Dominating Academic Language." International Higher Education 49: 2-4.

Altbach, P. G., and J. Salmi, eds. 2011. The Road to Academic Excellence: The Making of World-Class Research Universities. Washington, DC: World Bank.

Amin, A., and J. Roberts. 2008. "Knowing in Action: Beyond Communities of Practice." Research Policy 37 (2): 353-369. doi: 10.1016/j.respol.2007.11.003

Auriol, L. 2010. Careers of Doctorate Holders: Employment and Mobility Patterns. OECD Science, Technology and Industry Working Papers. Paris: OECD.

Basch, L., N. Glick Schiller, and C. Szanton Blanc. 1994. Nations Unbound: Transnational Projects, Postcolonial Predicaments, and Deterritorialized Nation-States. New York: Routledge.

Bathelt, H., A. Malmberg, and P. Maskell. 2004. "Clusters and Knowledge: Local Buzz, Global Pipelines and the Process of Knowledge Creation." Progress in Human Geography 28 (1): 31-56. doi: 10.1191/0309132504ph469oa 
Becher, T., and S. Parry. 2005. "The Endurance of the Disciplines." In Governing Knowledge, edited by I. Bleiklie and M. Henkel, 133-144. Dordrecht: Springer.

Becher, T., and P. Trowler. 2001. Academic Tribes and Territories. Buckingham: Open University Press.

Bilecen, B., and T. Faist. 2015. "International Doctoral Students as Knowledge Brokers: Reciprocity, Trust and Solidarity in Transnational Networks." Global Networks 15 (2): 217-235. doi: 10.1111/glob.12069

BIS. 2011. International Comparative Performance of the UK Research Base - 2011. London: Department of Business Innovation and Skills.

Bitusikova, A. 2012. POCARIM: Mapping the Population, Careers, Mobilities and Impacts of Advanced Research Degree Graduates in the Social Sciences and Humanities. Work Package 2: Policy Analysis. Salford: University of Salford.

Blackler, F. 1995. "Knowledge, Knowledge Work, and Organisations: An Overview and Interpretation." Organization Studies 16 (6): 1021-1046. doi: 10.1177/017084069501600605

Borchgrevink, H. M., and B. Scholz. 2012. New Concepts of Researcher Mobility: A Comprehensive Approach Including Combined/Part-Time Positions. Science Policy Briefing. Strasbourg: European Science Foundation.

Boschma, R. 2005. "Proximity and Innovation: A Critical Assessment." Regional Studies 39 (1): 61-74. doi: $10.1080 / 0034340052000320887$

Cañibano, C., E. Castro-Martínez, A. García-Aracil, F. J. Ortega-Colomer, J. Otamendi, and R. Woolley. 2013. POCARIM: Mapping the Population, Careers, Mobilities and Impacts of Advanced Research Degree Graduates in Social Sciences and Humanities. Work Package 3: Secondary Data Analysis. Salford: CSIC-UPV INGENIO.

Cañibano, C., J. Otamendi, and I. Andújar. 2008. "Measuring and Assessing Researcher Mobility from CV Analysis: The Case of the Ramón y Cajal Programme in Spain." Research Evaluation 17 (1): 1731. doi: 10.3152/095820208X292797

Cañibano, C., F. Otamendi, and F. Solís. 2011. "International Temporary Mobility of Researchers: A Cross-Discipline Study." Scientometrics Online: 1-23.

Edler, J., H. Fier, and C. Grimpe. 2011. "International Scientist Mobility and the Locus of Knowledge and Technology Transfer." Research Policy 40 (6): 791-805. doi: 10.1016/j.respol.2011.03.003

European Commission. 2010. "Europe 2020: Strategy for Smart, Sustainable and Inclusive Growth" (COM[2010] 2020). Brussels.

Fahey, J., and J. Kenway. 2010. "Thinking in a 'Worldly' Way: Mobility, Knowledge, Power and Geography." Discourse: Studies in the Cultural Politics of Education 31 (5): 627-640.

Faist, T. 2000. "Transnationalization in International Migration: Implications for the Study of Citizenship and Culture." Ethnic and Racial Studies 23 (2): 189-222. doi: 10.1080/014198700329024 
de Filippo, D., E. S. Casado, and I. Gómez. 2009. "Quantitative and Qualitative Approaches to the Study of Mobility and Scientific Performance: A Case Study of a Spanish University." Research Evaluation 18 (3): 191-200. doi: 10.3152/095820209X451032

Gustafsson, M., and T. B. Hanson. 2013. POCARIM: Mapping the Population, Careers, Mobilities and Impacts of Advanced Research Degree Graduates in Social Sciences and Humanities. Work Package 1: Research Review. Salford: Oxford Research AS.

Hannerz, U. 1990. “Cosmopolitans and Locals in World Culture." Theory Culture Society 7 (2): 237251. doi: $10.1177 / 026327690007002014$

Hantrais, L. 2009. International Comparative Research: Theory, Methods and Practice. Basingstoke: Palgrave MacMillan.

Hoffman, D. M. 2009. "Changing Academic Mobility Patterns and International Migration: What Will Academic Mobility Mean in the 21st Century?" Journal of Studies in International Education 13 (3): 347-364. doi: 10.1177/1028315308321374

Huang, F., M. Finkelstein, and M. Ros, eds. 2014. The Internationalization of the Academy: Changes, Realities and Prospects. Dordrecht: Springer.

IDEA Consult. 2013. Final Report MORE2: Support for Continued Data Collection and Analysis Concerning Mobility Patterns and Career Paths of Researchers. Brussels: European Commission.

Jonkers, K., and R. Tijssen. 2008. "Chinese Researchers Returning Home: Impacts of International Mobility on Research Collaboration and Scientific Productivity." Scientometrics 77 (2): 309-333. doi: 10.1007/s11192-007-1971-x

Jöns, H. 2002. "Grenzüberschreitende Mobilität und Kooperation in den Wissenschaften:

Deutschlandaufenthalte US-amerikanischer Humboldt-Forschungspreisträger aus einer erweiterten Akteursnetzwerkperspektive [Scientific Interaction Across Borders: An Actor-Network Based Approach to Research Stays of US Scientists in Germany, 1972-1996]." PhD diss, University of Heidelberg. http://archiv.ub.uni-heidelberg.de/volltextserver/2125/.

Jöns, H. 2007. "Transnational Mobility and the Spaces of Knowledge Production: A Comparison of Global Patterns, Motivations and Collaborations in Different Academic Fields." Social Geography 2 (2): 97-114. doi: 10.5194/sg-2-97-2007

Jöns, H. 2009. "'Brain Circulation' and Transnational Knowledge Networks: Studying Long-Term Effects of Academic Mobility to Germany, 1954-2000." Global Networks 9 (3): 315-338. doi: 10.1111/j.1471-0374.2009.00256.x

Jöns, H. 2011. "Transnational Academic Mobility and Gender." Globalisation, Societies and Education 9 (2): 183-209. doi: 10.1080/14767724.2011.577199

Jöns, H. 2015. "Talent Mobility and the Shifting Geographies of Latourian Knowledge Hubs." Population, Space and Place 21 (4): 372-389. doi: 10.1002/psp.1878

Jöns, H., E. Mavroudi, and M. Heffernan. 2015. "Mobilising the Elective Diaspora: US-German Academic Exchanges Since 1945." Transactions of the Institute of British Geographers 40 (1): 113127. doi: $10.1111 / \operatorname{tran} .12062$

Kaufmann, V., M. M. Bergman, and D. Joye. 2004. "Motility: Mobility as Capital." International Journal of Urban and Regional Research 28 (4): 745-756. doi: 10.1111/j.0309-1317.2004.00549.x 
Kim, T. 2009. "Shifting Patterns of Transnational Academic Mobility: A Comparative and Historical Approach." Comparative Education 45 (3): 387-403. doi: 10.1080/03050060903184957

Kim, T. 2010. "Transnational Academic Mobility, Knowledge, and Identity Capital." Discourse: Studies in the Cultural Politics of Education 31 (5): 577-591.

King, R. 2002. "Towards a New Map of European Migration." International Journal of Population Geography 8 (2): 89-106. doi: 10.1002/ijpg.246

King, R., and E. Ruiz-Gelices. 2003. "International Student Migration and the European 'Year Abroad': Effects on European Identity and Subsequent Migration Behaviour." International Journal of Population Geography 9 (3): 229-252. doi: 10.1002/ijpg.280

Knorr-Cetina, K. 1999. Epistemic Cultures: How the Sciences Make Knowledge. Cambridge: Harvard University Press.

Koehn, P., and J. N. Rosenau. 2010. Transnational Competence: Empowering Curriculums for HorizonRising Challenges. Boulder, CO: Paradigm.

Krishnan, A. 2009. What Are Academic Disciplines? Some Observations on the Disciplinarity vs. Interdisciplinarity Debate. Working Papers. Southampton: ERSC National Centre for Research Methods (NCRM).

Kupiszewska, D., M. Kupiszewski, A. Kicinger, L. Ackers, and C. Coey. 2013. POCARIM: Mapping the Population, Careers, Mobilities and Impacts of Advanced Research Degree Graduates in Social Sciences and Humanities. Work Package 4: Survey. Salford: CEFMR/IOM.

Larner, W. 2015. "Globalising Knowledge Networks: Universities, Diaspora Strategies, and Academic Intermediaries." Geoforum; Journal of Physical, Human, and Regional Geosciences 59: 197-205.

Levitt, P., and N. Glick Schiller. 2004. "Conceptualizing Simultaneity: A Transnational Social Field Perspective on Society." International Migration Review 38 (3): 1002-1039. doi: 10.1111/j.17477379.2004.tb00227.x

Mahroum, S. 2000a. "Global Magnets: Science and Technology Disciplines and Departments in the United Kingdom." Minerva 37 (4): 379-390. doi: 10.1023/A:1004749905956

Mahroum, S. 2000b. "Scientific Mobility: An Agent of Scientific Expansion and Institutional Empowerment." Science Communication 21 (4): 367-378. doi: 10.1177/1075547000021004003

Mahroum, S. 2008. UK Global Innovation: Engaging with New Countries, Regions and People. London: National Endowment for Science, Technology and the Arts (NESTA). https://www.nesta.org.uk/sites/default/files/uk global innovation report.pdf.

Meusburger, P. 2008. "The Nexus Between Knowledge and Space." In Clashes of Knowledge: Orthodoxies and Heterodoxies in Science and Religion, edited by P. Meusburger, M. Welker, and E. Wunder, 35-90. Dordrecht: Springer.

Meyer, M., and S. Molyneux-Hodgson. 2010. "Introduction: The Dynamics of Epistemic Communities." Sociological Research Online 15 (2): 14.

Mihut, G., A. de Gayardon, and Y. Rudt. 2017. "The Long-Term Mobility of International Faculty: A Literature Review." In International Faculty in Higher Education: Comparative Perspectives on 
Recruitment, Integration, and Impact, edited by M. Yudkevich, P. G. Altbach, and L. E. Rumbley, 1531. Abingdon: Routledge.

Murphy-Lejeune, E. 2002. Student Mobility and Narrative in Europe: The New Strangers. New York: Routledge.

Nonaka, I., and H. Takeuchi. 1995. The Knowledge-Creating Company: How Japanese Companies Create the Dynamics of Innovation. New York: Oxford University Press.

OECD. 2007. Higher Education and Regions: Globally Competitive, Locally Engaged. Paris: Organisation for Economic Co-operation and Development.

Polanyi, M. 1958. Personal Knowledge. London: Routledge.

Polanyi, M. 1966. The Tacit Dimension. New York: Doubleday and Company Inc.

Robinson-Pant, A. 2009. “Changing Academies: Exploring International PhD Students' Perspectives on 'Host' and 'Home' Universities." Higher Education Research \& Development 28 (4): 417-429. doi: 10.1080/07294360903046876

Rossi, U. 2008. "Being Here and There: In-Betweeness, Double Absence, and the Making of a MultiLayered Academic Citizenship." Area 40 (3): 401-406. doi: 10.1111/j.1475-4762.2008.00816.x

Rostan, M., and E. A. Höhle. 2014. "The International Mobility of Faculty." In The Internationalization of the Academy: Changes, Realities and Prospects, edited by F. Huang, M. Finkelstein, and M. Ros, 79-104. Dordrecht: Springer.

Storme, T., J. R. Faulconbridge, J. V. Beaverstock, B. Derudder, and F. Witlox. 2016. "Mobility and Professional Networks in Academia: An Exploration of the Obligations of Presence." Mobilities 12 (3): 405-424. doi: 10.1080/17450101.2015.1116884

Teichler, U. 2011. "Academic Staff Mobility." In Mapping Mobility in European Higher Education Volume I: Overview and Trends, edited by U. Teichler, I. Ferencz, and Wächter, 111-146. Brussels: European Commission.

van Oorschot, I. 2014. "Negotiating Knowledges Abroad: Non-Western Students and the Global Mobility of Knowledge." Compare: A Journal of Comparative and International Education 44 (6): 895-915. doi: 10.1080/03057925.2013.824782

Velema, T. 2011. "The Contingent Nature of Brain Gain and Brain Circulation: Their Foreign Context and the Impact of Return Scientists on the Scientific Community in Their Country of Origin." Scientometrics 93 (3): 1-21.

Waters, J. L., and M. Leung. 2013. "Immobile Transnationalisms? Young People and Their in situ Experiences of 'International' Education in Hong Kong." Urban Studies 50: 606-620. doi: $10.1177 / 0042098012468902$

Welch, A. 2008. "Myths and Modes of Mobility: The Changing Face of Academic Mobility in the Global Era." In Students, Staff and Academic Mobility in Higher Education, edited by M. Byram and F. Dervin, 292-311. Cambridge: Cambridge Scholars Publishing.

Wenger, E. 1998. Communities of Practice: Learning, Meaning, and Identity. Cambridge: Cambridge University Press.

Williams, A. M., and V. Baláž. 2008. International Migration and Knowledge. Abingdon: Routledge. 
Williams, A. M., V. Baláz, and C. Wallace. 2004. "International Labour Mobility and Uneven Regional Development in Europe: Human Capital, Knowledge and Entrepreneurship." European Urban and Regional Studies 11 (1): 27-46. doi: 10.1177/0969776404039140

\section{Additional information}

Funding

This work was supported by the European Union's Seventh Framework Programme under [grant number 290770]. 